\title{
Stereochemistry of Silicon
}

\author{
BØRGE BAK, JøRGEN BRUHN and JOHN RASTRUP.ANDERSEN
}

\author{
Chemical Laboratory of the University of Copenhagen, Copenhagen, Denmark
}

\begin{abstract}
New measurements of microwave frequencies of $\mathrm{SiD}_{2} \mathrm{Cl}$ and $\mathrm{SiD}_{3} \mathrm{~F}$ in conjunction with earlier measurements on $\mathrm{SiH}_{3} \mathrm{Cl}$ and $\mathrm{SiH}_{3} \mathrm{~F}$ enable the authors to calculate the silicon-chlorine distance in ordinary and deuterated silyl chlorides. The results were $2.0479 \pm 0.0007 \AA$ and $2.0486 \pm 0.0007 \AA$ respectively. The silicon-fluorine distances in ordinary and deuterated silylfluorides were found to be $1.595 \pm 0.010$ $\AA$ in both cases.

Silicon-hydrogen and silicon-deuterium distances and the valence angles were estimated. The changes in these quantities caused by the substitution of one hydrogen atom in silane by chlorine or fluorine are small and about the same as in the pairs $\mathrm{CH}_{4}, \mathrm{CH}_{3} \mathrm{Cl}$ and $\mathrm{CH}_{4}$, $\mathrm{CH}_{3} \mathrm{~F}$.

Preparation and properties of $\mathrm{SiD}_{3} \mathrm{Cl}$ and $\mathrm{SiD}_{3} \mathrm{~F}$ are described.
\end{abstract}

Tn the classical paper by Kipping ${ }^{1}$ it was shown that compounds of the 1 type SiXYZW, where $X, Y, Z$, and $W$ are mono-valent radicals, can be separated into optical isomers. This excludes a planar arrangement of silicon and its four ligands. Later, X-ray determination of the crystal structure of $\mathrm{SiI}_{4}$ by Hassel and Kringstad ${ }^{2}$ revealed that the four iodine atoms were situated in the corners of a regular tetrahedron with silicon in the centre. A pyramidal arrangement with silicon at the top was thereby eliminated. A similar result for $\mathrm{SiH}_{4}$ was found by Tindal, Straley and Nielsen ${ }^{3}$ by the use of infrared technique. Since the bonds of tetrahedral $\mathrm{SiX}_{4}$ molecules almost by necessity must be directed towards the corners of a regular tetrahedron the interesting problem of the direction and magnitude of possible deviations from regularity in cases like $\mathrm{SiX}_{3} \mathrm{Y}, \mathrm{SiX}_{2} \mathrm{Y}_{2}$ etc. remained to be solved. In a number of cases where electron-diffraction technique could be applied ${ }^{4-6}$ deviations were found but the results were too inaccurate to give more than a rough idea of the angular and linear irregularities so demonstrated.

By the advent of microwave technique (1945-46) conditions for further progress again became favourable. 1948, Sharbaugh ${ }^{7}$ published measurements on $\mathrm{Si}^{28} \mathrm{H}_{3} \mathrm{Cl}^{35}$ and $\mathrm{Si}^{28} \mathrm{H}_{3} \mathrm{Cl}^{37}$. 1949, Townes and collaborators ${ }^{8}$ found the microwave absorption of $\mathrm{Si}^{30} \mathrm{H}_{3} \mathrm{Cl}^{35}$. In 1950 , Sharbaugh and collaborators ${ }^{9}$ published their results for the three isotopic species $\mathrm{Si}^{28,29,30} \mathrm{H}_{3} \mathrm{~F}$. . All three 
papers agreed in the statement that the silyl halides examined are symmetric tops. Such molecules have two different principal moments of inertia. The smaller moment (about the Si-halogen axis) we shall consistingly denote by $I_{A}$, the greater by $I_{B}$ (adding, of course, extra symbols if we want to indicate the moment of a particular molecule). It is easy to derive that

$$
\left(I_{\mathrm{B}}-\frac{1}{2} I_{\mathrm{A}}\right) m_{\mathrm{SIY}, \mathrm{X}}=a^{2} m_{\mathrm{S} 1} m_{\mathrm{X}}+3\left(a+d_{\mathrm{Y}} \cos \varphi_{\mathrm{Y}}\right)^{2} m_{\mathrm{Y}} m_{\mathrm{X}}+3 d_{\mathrm{Y}}^{2} \cos ^{2} \varphi_{\mathrm{Y}} m_{\mathrm{SI}} m_{\mathrm{Y}}
$$

where $\mathrm{Si}$ is a silicon isotope, $\mathrm{Y}$ a hydrogen isotope and $\mathrm{X}$ a halogen atom. $m_{\mathrm{SiY}} \mathrm{X}$ is the mass of $\mathrm{SiY}_{3} \mathrm{X}, a$ is the $\mathrm{Si}-\mathrm{X}$ distance, $d_{\mathbf{Y}}$ the $\mathrm{Si}-\mathrm{Y}$ distance. $\varphi_{\mathrm{Y}}$ is the supplementary angle of the $\mathrm{X}-\mathrm{Si}-\mathrm{Y}$ angle. The relation between observed microwave absorption frequency, $\nu_{\mathrm{obe}}\left(\mathrm{cm}^{-1}\right)$, and $I_{\mathrm{B}}$ is

$$
\nu_{\text {obs }}=\frac{h}{4 \pi^{2} c I_{\mathrm{B}}}(J+1)=2 B(J+1)
$$

where $J$ is the rotational quantum number of the lower of the two states involved, $c$ the velocity of light and $B$ the rotational constant. Experience has shown that (2) reproduces microwave spectra to a high degree of accuracy for small $J$-values. The highest $J$ to be used in the following is $J=1$. Unfortunately, microwave spectra of symmetric tops tell nothing of $I_{\mathrm{A}}$. If, therefore, microwave absorption for, say, $\mathrm{Si}^{29} \mathrm{D}_{3} \mathrm{Cl}^{35}$ is observed, only the magnitude of $I_{\mathrm{B}}$ (in this case denoted by $I_{\mathrm{B}}{ }^{29, D, 35}$ ) results. This information is insufficient for a calculation of the three geometrical parameters, $a, d_{\mathbf{Y}}$, and $\varphi_{\mathbf{Y}}$. If it is assumed, however, that isotopic molecules have identical dimensions, it is seen that observation of microwave absorption for at least three isotopic species of the same compound enables one to carry through a calculation of $a, d_{\mathbf{y}}$, and $\varphi_{\mathrm{Y}}$. This was what was actually done by Townes et al..$^{8}$ in the case of silyl chloride. They found $a=2.050 \pm 0.001 \AA ; d_{\mathrm{H}}=1.50 \AA ; \varphi_{\mathrm{H}}=72^{\circ} 2^{\prime}$, but the magnitude of the two last-mentioned parameters must have been difficult to fix because of the quasi-degeneracy of the equations to solve. To avoid this complication Sharbaugh et al. ${ }^{9}$ chose, in the case of silyl fluoride, to assume that $\varphi_{\mathrm{H}}=72^{\circ} 6^{\prime}$. They calculated $a=1.593 \pm 0.002 \AA$ and $d_{\mathrm{H}}=1.50 \pm 0.03 \AA$. Now, in the paper by Nielsen ${ }^{3}$ it was shown that $d_{\mathbf{H}}=1.456 \mathrm{~A}$ in $\mathrm{SiH}_{4}$. (Here, $\varphi_{\mathbf{H}}=70^{\circ} 32^{\prime}$ ). So far it looked, therefore, as if substitution of one hydrogen atom in $\mathrm{SiH}_{4}$ by fluorine or chlorine would cause fairly large changes in the remaining Si-H bonds. Since this is definitely known not to be the case for the methyl halides it was decided to provide further experimental material in order to be able to calculate $d_{H}$ and $\varphi_{H}$ with somewhat higher accuracy.

\section{EXPERIMENTAL PART}

Preparation of $\mathrm{SiD}_{3} \mathrm{Cl}$ and $\mathrm{SiD}_{2} \mathrm{~F}$ (B. B. and J.B.). $4 \mathrm{~g} \mathrm{Mg}_{2} \mathrm{Si}$ (from $\mathrm{Mg}$ and $\mathrm{Si}$ )

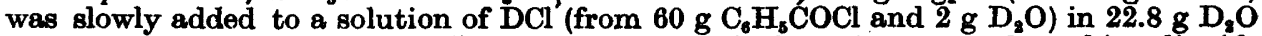
in a stream of dry hydrogen. $\mathrm{SiD}_{4}$ and impurities $\left(\mathrm{Si}_{8} \mathrm{D}_{6}\right.$ etc.) were condensed in a liquid. air trap. After evacuation at $-190^{\circ} \mathrm{C}$ the temperature of the trap was raised to $-125^{\circ} \mathrm{C}$. The pressure rose to $380 \mathrm{~mm} \mathrm{Hg}$. In small portions the vapors were admitted to an adjacent, evacuated trap cooled in liquid air, until the vapor-pressure in the trap at $125^{\circ} \mathrm{C}$ had fallen to $35 \mathrm{~mm} \mathrm{Hg}$. The rest was discarded and the collected material transferred to a container, kept at $-118^{\circ} \mathrm{C}$ from which practically the whole sample could be distilled at $470 \mathrm{~mm} \mathrm{Hg}$. In this way $100 \mathrm{ml}$ portions were repeatedly prepared ( $1 \mathrm{~atm} ., 20^{\circ} \mathrm{C}$ ), representing a $8 \%$ yield of $\mathrm{SiD}_{4}$ (based on $\mathrm{Mg}_{2} \mathrm{Si}$ ). 
$52 \mathrm{ml} \mathrm{SiD}$ ( $\left(1 \mathrm{~atm} ., 20^{\circ} \mathrm{C}\right.$ ) were brought to reaction with $38 \mathrm{ml} \mathrm{DCl}\left(1 \mathrm{~atm} ., 20^{\circ} \mathrm{C}\right.$ ) over $\mathrm{AlCl}_{3}$ (resublimed) at $100^{\circ} \mathrm{C}$ in a $120 \mathrm{ml}$ flask. Contact between the reaction mixture and the greased stopcock was prevented by means of a drop of mercury. After three hours the reaction mixture:

$$
\begin{gathered}
\mathrm{SiD}_{4}+\mathrm{DCl} \rightleftharpoons \mathrm{SiD}_{3} \mathrm{Cl}+\mathrm{D}_{2} \\
\mathrm{SiD}_{3} \mathrm{Cl}+\mathrm{DCl} \rightleftharpoons \mathrm{SiD}_{2} \mathrm{Cl}_{2}+\mathrm{D}_{2} \text { etc. }
\end{gathered}
$$

was cooled in liquid air. The deuterium formed $\left(27 \mathrm{ml}\right.$ at $\left.1 \mathrm{~atm} ., 20^{\circ} \mathrm{C}\right)$ was pumped off and the remaining $63 \mathrm{ml}$ gases were carefully fractionated. $20 \mathrm{ml} \mathrm{SiD}{ }_{8} \mathrm{Cl}$ (vapor-pressure $45 \mathrm{~mm} \mathrm{Hg}$ at $-72^{\circ} \mathrm{C}$ ) were collected. Yield: $40 \%$ based on $\mathrm{SiD}_{4}$. The sample so obtained was practically free of $\mathrm{SiD}_{2} \mathrm{HCl}$ since no line corresponding to the $\mathrm{Si}-\mathrm{H}$ vibration could be seen in the infrared absorption spectrum. The mierowave spectrum showed that it was also free of $\mathrm{SiD}_{2} \mathrm{Cl}_{2}$. $\mathrm{SiD}_{3} \mathrm{Cl}$ (and $\mathrm{SiH}_{3} \mathrm{Cl}$ ) can be stored for months at $-78^{\circ} \mathrm{C}$ in a glass container without undergoing any change. At room temperature and $0.5-1 \mathrm{~atm}$. it is likewise stable for shorter periods ( $1-2$ hours). In handling the compound it is impor. tant to note that even a trace of water converts it very rapidly into $\left(\mathrm{SiD}_{3}\right)_{2} \mathrm{O}$ from which it is hard to separate.

$\mathrm{SiH}_{3} \mathrm{~F}$ has earlier been produced from $\mathrm{SiH}_{3} \mathrm{Cl}$ and $\mathrm{SbF}_{8}$ (catalyst: $\mathrm{SbCl}_{5}$ ). In preliminary experiments it was shown that the use of $\mathrm{SbCl}_{5}$ is superfluous. The following procedure was finally followed: $9.1 \mathrm{ml} \mathrm{SiD} \mathrm{Cl}_{3} \mathrm{Cl}$ atm., $20^{\circ} \mathrm{C}$ ) was left for 12 hours in a $12 \mathrm{ml}$ flask (greased stopcock protected by mercury) in contact with $250 \mathrm{mg}$ resublimed $\mathrm{SbF}_{3}$. Then the flask was cooled in liquid air and subsequently evacuated $\left(0.2 \mathrm{ml} \mathrm{D}_{2}\right.$ was formed). The reaction mixture was fractionated at $-118^{\circ} \mathrm{C}$ where a constant-boiling fraction $\left(4.4 \mathrm{ml}\left(1 \mathrm{~atm} ., 20^{\circ} \mathrm{C}\right)\right.$ ) was obtained at $46 \mathrm{~mm} \mathrm{Hg}$. The infrared absorption spectrum showed no sign of the presence of hydrogen-containing compounds, but both microwave and infrared absorption curves showed that probably the sample was contaminated with $\mathrm{SiD}_{2} \mathbf{F}_{2}$. Since, however, the Stark patterns used in microwave spectroscopy are widely different for symmetric tops $\left(\mathrm{SiD}_{3} \mathrm{~F}\right)$ and asymmetric rotors $\left(\mathrm{SiD}_{2} \mathrm{~F}_{2}\right)$ the unambigous identification of a microwave line as originating from $\mathrm{SiD}_{3} \mathrm{~F}$ is not prevented.

\section{MEASUREMENT OF MICROWAVE ABSORPTION OF $\mathrm{SiD}_{3} \mathrm{Cl}$ AND $\mathrm{SiD}_{3} \mathrm{~F}$.} (B. B. AND J. R-A.)

Since both silicon and chlorine consist of a mixture of stable isotopes of rather high concentration $\left(\mathrm{Si}^{28}: 90 \% ; \mathrm{Si}^{29}: 6 \% ; \mathrm{Si}^{30}: 4 \% ; \mathrm{Cl}^{35}: 75 \%\right.$; $\mathrm{Cl}^{37}: 25 \%$ ) 'heavy' silyl chloride is a mixture of 6 isotopic species while 'heavy' silyl fluoride is composed of 3 species. Microwave absorption corresponding to four of the chlorides and all three fluorides was found (Table 1).

Table 1. Observed microwave absorption frequencies for isotopic silyl fluoride and chloride

\begin{tabular}{|c|c|c|c|c|}
\hline Species & Transition & $\nu_{\text {obs }} \mathrm{MHz}$ & $I_{\mathrm{B}} \times 10^{40} \mathrm{gcm}^{2}$ & $B \mathrm{MHz}$ \\
\hline $\begin{array}{l}\mathrm{Si}^{28} \mathrm{D}_{3} \mathrm{~F} \\
\mathrm{Si}^{20} \mathrm{D}_{3} \mathrm{~F} \\
\mathrm{Si}^{30} \mathrm{D}_{3} \mathrm{~F} \\
\mathrm{Si}^{28} \mathrm{D}_{3} \mathrm{Cl} \\
\mathrm{Si}^{35} \mathrm{D}_{3} \mathrm{Cl}^{35} \\
\mathrm{Si}^{30} \mathrm{D}_{3} \mathrm{Cl}^{35} \\
\mathrm{Si}^{28} \mathrm{D}_{3} \mathrm{Cl}^{37}\end{array}$ & $\begin{array}{c}J=0 \rightarrow 1 \\
J=1 " \\
" ~\end{array}$ & $\begin{array}{l}24507.0 \\
24352.2 \\
24204.5 \\
23670.8 \\
23402.6 \\
23147.9 \\
23091.4 \\
\end{array}$ & $\begin{array}{r}68.461 \\
68.897 \\
69.316 \\
141.759 \\
143.383 \\
144.961 \\
145.316 \\
\end{array}$ & $\begin{array}{r}\mathbf{1 2 2 5 3 . 5} \\
\mathbf{1 2 1 7 6 . 1} \\
\mathbf{1 2 1 0 2 . 2} \\
\mathbf{5 9 1 7 . 7} \\
\mathbf{5 8 5 0 . 6} \\
\mathbf{5 7 8 7 . 0} \\
\mathbf{5 7 7 2 . 8} \\
\end{array}$ \\
\hline $\begin{array}{l}\mathrm{Si}^{28} \mathrm{H}_{3} \mathrm{~F} \\
\mathrm{Si}^{20} \mathrm{H}_{3} \mathrm{~F} \\
\mathrm{Si}^{30} \mathrm{H}_{8} \mathrm{~F} \\
\mathrm{Si}^{28} \mathrm{H}_{3} \mathrm{Cl}^{35} \\
\mathrm{Si}^{80} \mathrm{H}_{3} \mathrm{Cl}^{36} \\
\mathrm{Si}^{28} \mathrm{H}_{8} \mathrm{Cl}^{37}\end{array}$ & $\begin{array}{c}J=0 \rightarrow 1 \\
J=1 "\end{array}$ & $\begin{array}{l}28655.8 \\
28393.4 \\
28145.2 \\
26695.2 \\
25943.2 \\
26049.6 \\
\end{array}$ & $\begin{array}{r}\mathbf{5 8 . 5 4 9} \\
\mathbf{5 9 . 0 9 0} \\
\mathbf{5 9 . 6 1 1} \\
\mathbf{1 2 5 . 6 9 8} \\
\mathbf{1 2 9 . 3 4 2} \\
\mathbf{1 2 8 . 8 1 3} \\
\end{array}$ & $\begin{array}{r}14327.9 \\
14196.7 \\
14072.6 \\
6673.8 \\
6485.8 \\
6512.4 \\
\end{array}$ \\
\hline
\end{tabular}
molecules.

Acta Chem. Scand. 8 (1954) No. 3 
The observations placed below the line in the middle of Table 1 were made by the previously cited authors ${ }^{2 \rightarrow}$. Due to the spin of the chlorine nucleus the microwave absorption of all the chlorides exhibits a hyperfine structure. Since the quadrupole coupling is very nearly the same for light and heavy silyl chloride the correction terms for quadrupole coupling found by Sharbaugh 7 for $\mathrm{SiH}_{3} \mathrm{Cl}^{35}$ and $\mathrm{SiH}_{3} \mathrm{Cl}^{37}$ could be taken over without appreciable error. The value $h=6.6237 .10^{-27}$ ergsec was used for Planck's constant in calculating $I_{B}$.

\section{MOLECULAR DIMENSIONS OF SILYL CHLORIDE AND FLUORIDE.}

$$
\text { a. Silyl chloride }
$$

It is easy to derive from (1) that

$$
\begin{aligned}
a_{\mathrm{H}} \frac{m_{\mathrm{Cl}^{35}}}{m_{\mathrm{H}}}-3 d_{\mathrm{H}} \cos \varphi_{\mathrm{H}} & =K^{30-28, \mathrm{H}, 35} \\
a_{\mathrm{H}} \frac{m_{\mathrm{Si}^{1 \mathrm{H}_{2}}}}{m_{\mathrm{H}}}+3 d_{\mathrm{H}} \cos \varphi_{\mathrm{H}} & =K^{28, \mathrm{H}, 37-35}
\end{aligned}
$$

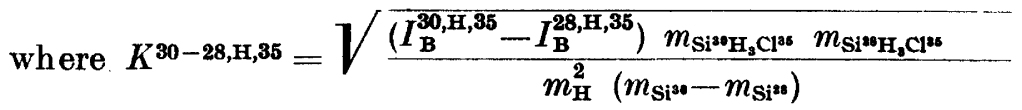

and $K^{28, \mathrm{H}, 37-35}=\sqrt{\frac{\left(I_{\mathrm{B}}^{28, \mathrm{H}, 37}-I_{\mathrm{B}}^{28, \mathrm{H}, 35}\right) m_{\mathrm{Si}^{18} \mathrm{H}_{3} \mathrm{Cl}^{137}} m_{\mathrm{Si}^{18} \mathrm{H}_{3} \mathrm{Cl}^{38}}}{m_{\mathrm{H}}^{2}\left(m_{\mathrm{C}^{37}}-m_{\mathrm{Cl}^{35}}\right)}}$

In the calculations to follow the atomic masses used were:

$\mathrm{Si}^{28}$ : 27.9866; $\mathrm{Si}^{29}: 28.9866 ; \mathrm{Si}^{30}: 29.9832: \mathrm{Cl}^{35}$ : 34.9786 ;

$\mathrm{Cl}^{37}$ : 36.9775; F: 19.0049; H: 1.008123; D: 2.014708,

all in the physical atomic weight scale. The corresponding value of Avogadros number used is $6.0251 \cdot 10^{23}$.

By addition of (3) and (4) a formula giving $a_{\mathrm{H}}$ as a function of measured quantities is easily derived (5):

$$
a_{\mathrm{H}}=\frac{m_{\mathrm{H}}}{m_{\mathrm{Si}^{12} \mathrm{H}_{2} \mathrm{C}^{155}}}\left(K^{30-28, \mathrm{H}, 35}+K^{28, \mathrm{H}, 37-35}\right)
$$

By insertion it is found that

$$
a_{\mathrm{H}}=2.0479 \AA
$$

Microwave absorption frequencies of silyl chloride and fluoride molecules not containing the rare isotopes $\mathrm{Si}^{29}$ and $\mathrm{Si}^{30}$ are reliable to $\pm 0.2 \mathrm{MHz}$, while the rest may be assumed to be good to $\pm 0.3 \mathrm{MHz}$. This means an uncertainty in the calculated $a_{\mathbf{H}}$ value of 7 in the fourth decimal place so that

$$
2.0472 \AA<a_{\mathrm{H}}<2.0486 \AA
$$

If a similar calculation is carried through in order to find $a_{\mathrm{D}}$, the Si-Cl distance in the 'heavy' species, we find that

$$
a_{\mathrm{D}}=2.0486 \AA \text { and that } 2.0479 \AA<a_{\mathrm{D}}<2.0493 \AA
$$


The values of $a_{\mathrm{H}}$ and $a_{\mathrm{D}}$ refer to the molecules in their ground state where the only internal energy left is the zero-point energy. In their ground state isotopic molecules do not possess identical structures but only very nearly so. Since the zero-point energy may be thought of as kinetic and since of two isotopic molecules the lighter has the higher zero-point energy this means that as a rule bond lengths will decrease slightly with increasing molecular weight in a series of isotopic molecules. In the calculations above it was tacitly assumed that the very small differences in zero-point energy between molecules which only differ in silicon or chlorine isotopes, have no effect on the interatomic distances. However, molecules differing in hydrogen isotopes have rather different zero-point energies. Here, we may expect structural differences which, due to the small masses of hydrogen and deuterium, must be expected to be most pronounced in the magnitude of the parameters $d_{\mathrm{H}}, d_{\mathrm{D}}, \varphi_{\mathrm{H}}$, and $\varphi_{\mathrm{D}}$. Indeed, the values found for $a_{\mathrm{H}}$ and $a_{\mathrm{D}}$ verify this assumption. Generally it must be expected that $d_{\mathrm{H}}>d_{\mathrm{D}}$ and $\varphi_{\mathrm{H}} \neq \varphi_{\mathrm{D}}$. In the case of the methyl halides Miller, Aamodt, Dousmanis and Townes ${ }^{10}$ got the results of Table 2.

Table 2. Position of hydrogen and deuterium atoms in light and heavy methyl halides.

\begin{tabular}{|c|c|c|c|c|c|c|c|c|}
\hline & $d_{\mathrm{H}}, d_{\mathrm{D}}$ & $\varphi_{\mathrm{H}}, \varphi_{\mathrm{D}}$ & & $d_{\mathrm{H}}, d_{\mathrm{D}}$ & $\varphi_{\mathrm{H}}, \varphi_{\mathrm{D}}$ & & $d_{\mathrm{H}}, d_{\mathrm{D}}$ & $\varphi_{\mathrm{H}}, \varphi_{\mathrm{D}}$ \\
\hline $\begin{array}{l}\mathrm{CH}_{3} \mathrm{Cl} \\
\mathrm{CD}_{3} \mathrm{Cl}\end{array}$ & $\begin{array}{l}1.113 \\
1.104 \\
\end{array}$ & $\begin{array}{l}71^{\circ} 36^{\prime} \\
71^{\circ} 50^{\prime} \\
\end{array}$ & $\begin{array}{l}\mathrm{CH}_{3} \mathrm{Br} \\
\mathrm{CD}_{3} \mathrm{Br} \\
\end{array}$ & $\begin{array}{l}1.113 \\
1.104 \\
\end{array}$ & $\begin{array}{l}72^{\circ} 21^{\prime} \\
72^{\circ} 34^{\prime} \\
\end{array}$ & $\begin{array}{l}\mathrm{CH}_{3} \mathrm{~J} \\
\mathrm{CD}_{3} \mathrm{~J}\end{array}$ & $\begin{array}{l}1.113 \\
1.104 \\
\end{array}$ & $\begin{array}{l}72^{\circ} 33 \\
\mathbf{7 2 ^ { \circ }} 46^{\prime} \\
\end{array}$ \\
\hline$d_{\mathrm{H}}-d_{\mathrm{D}}$ & 0.009 & & & 0.009 & & & 0.009 & \\
\hline$\varphi_{\mathrm{D}}-\varphi_{\mathrm{H}}$ & & $14^{\prime}$ & & & $13^{\prime}$ & & & 13 \\
\hline $\begin{array}{c}\text { Deviations } \\
\quad \text { from } \mathrm{CH}_{4}\end{array}$ & $\begin{array}{l}0.02 \\
0.01\end{array}$ & $\begin{array}{l}1^{\circ} \quad 4^{\prime} \\
1^{\circ} \quad 8^{\prime}\end{array}$ & & $\begin{array}{l}0.02 \\
0.01\end{array}$ & $\begin{array}{l}1^{\circ} \mathbf{4 9}^{\prime} \\
2^{\circ} 2^{\prime}\end{array}$ & & $\begin{array}{l}0.02 \\
0.01\end{array}$ & $\begin{array}{l}2^{\circ} 1^{\prime} \\
2^{\circ} 1^{14}\end{array}$ \\
\hline
\end{tabular}

For the silyl chlorides and fluorides deviations from regularity of the same order of magnitude were found by Bak, Rastrup-Andersen and Bruhn ${ }^{12}$. Since then, Monfils ${ }^{11}$ has studied the fine-structure of the infrared bands of silyl chloride. $\mathrm{He}$ found $I_{\mathrm{A}}^{28, \mathrm{H}, 35}=(9.89 \pm 0.15) \times 10^{-40} \mathrm{gcm}^{2}$. Strictly spoken this result probably is a 'hybrid' between the true $I_{\mathrm{A}}^{28, \mathrm{H}, 35}$ (vibrational ground level) and $I_{\mathrm{A}}$ for a vibrationally excited level (such details cannot be seen from Monfils' note) but the error committed by setting $I_{\mathrm{A}}^{28, \mathrm{H}, 35}=\mathbf{9 . 8 9}$ $10^{-10} \mathrm{gcm}^{2}$ cannot be great. (In the case of OCS it has been found that the moment of inertia of a molecule, vibrationally excited by one quantum, deviated less than $0.5 \%$ from the moment in the ground state.)

By inserting the calculated value of $a_{\mathrm{H}}$ in (3) we find that

$$
\begin{gathered}
d_{\mathrm{H}} \cos \varphi_{\mathrm{H}}=0.476 \pm 0.002 \AA \\
I_{\mathrm{A}}^{28, \mathrm{H}, 35}=3 m_{\mathrm{H}} d_{\mathrm{H}}^{2} \sin ^{2} \varphi_{\mathrm{H}}=(9.89 \pm 0.15) \times 10^{-40} \mathrm{gcm}^{2} \text { gives } \\
d_{\mathrm{H}} \sin \varphi_{\mathrm{H}}=1.405 \pm 0.012 \AA
\end{gathered}
$$

Acta Chem. Scand. 8 (1954) No. 3 
It follows that

$$
\begin{aligned}
& \varphi_{\mathrm{H}}=71^{\circ} 15^{\prime} \pm 15^{\prime} \text { and } d_{\mathrm{H}}=1.483 \AA \pm 0.010 \AA \\
& \text { In } \mathrm{SiH}_{4}, \quad \varphi_{\mathrm{H}}=70^{\circ} 32^{\prime} \quad \text { " } d_{\mathrm{H}}=1.456 \AA \pm 0.010 \AA
\end{aligned}
$$

The deviation in $\varphi_{\mathrm{H}}$ and $d_{\mathrm{H}}$, are, therefore, respectively $43^{\prime}$ and $0.027 \AA$. These numbers correspond very well with what was found for methyl chloride (Table 2). The results suggest that $d_{D}$, the $\mathrm{Si}-\mathrm{D}$ distance in the heavy silyl chloride, may be one or two hundredths of an $\AA$ smaller than $d_{\mathrm{H}}$ as found for methyl chloride. Consequently we look for solutions in the region where $1.49 \AA \geqq d_{D} \geqq 1.46 \AA$. The point of interest now is whether we shall find $\varphi_{D}$ to be close to and a little greater than $\varphi_{\mathrm{H}}$.

By inserting the value of $a_{\mathrm{D}}$ calculated above in the 'heavy' equation corresponding to $(3)$ we find $d_{\mathrm{D}} \cos \varphi_{\mathrm{D}}=0.469 \pm 0.002 . d_{\mathrm{D}}=1.460 \AA$, therefore, corresponds to $\varphi_{\mathrm{D}}=71^{\circ} 11^{\prime}-71^{\circ} 21^{\prime}$ while $d_{\mathrm{D}}=1.490 \AA$ corresponds to $\varphi_{\mathrm{D}}=71^{\circ} 34^{\prime}-71^{\circ} 44^{\prime}$. It is seen that $\varphi_{\mathrm{D}}$ and $\varphi_{\mathrm{H}}$ are about equal. Furthermore it is seen that if we fix $d_{\mathrm{H}}$ to $1.483 \AA$ and if we suppose that $d_{\mathrm{H}}-d_{\mathrm{D}}=0.009 \AA$ as in $\mathrm{CH}_{3} \mathrm{Cl}$ we get $\varphi_{\mathrm{D}}=71^{\circ} 27^{\prime}$ (mean value) which happens to be $12^{\prime}$ greater than $\varphi_{\mathrm{H}}$. For $\mathrm{CH}_{3} \mathrm{Cl}$ and $\mathrm{CD}_{3} \mathrm{Cl}$ this difference was found to be 14' (Table 2).

\section{b. Silyl fluoride}

Not much could be added to the communication by Bak, Bruhn and Rastrup-Andersen 12. Due to the lack of fluorine isotopes an equation like (5) cannot be derived giving the silicon-fluorine distance as a function of measured quantities. Since

and

$$
a_{\mathrm{H}} \frac{m_{\mathrm{F}}}{m_{\mathrm{H}}}-3 d_{\mathrm{H}} \cos \varphi_{\mathrm{H}}=K^{30-28, \mathrm{H}, \mathrm{F}}
$$

we can derive $a=\frac{m_{\mathrm{H}} m_{\mathrm{D}}}{m_{\mathrm{F}}\left(m_{\mathrm{D}}-m_{\mathrm{H}}\right)}\left\{K^{30-28, \mathrm{H}, \mathrm{F}}-K^{30-28, \mathrm{D}, \mathrm{F}}+3\left(d_{\mathrm{H}} \cos \varphi_{\mathrm{H}}-\right.\right.$

$$
\left.\left.-d_{\mathrm{D}} \cos \varphi_{\mathrm{D}}\right)\right\}
$$

where the difference between $a_{\mathrm{H}}$ and $a_{\mathrm{D}}$ has been neglected which was found to be correct for silyl chloride.

By omitting the last term of this equation we find

$$
a=1.595 \pm 0.002 \AA
$$

If we assume that $\left|d_{\mathrm{H}}-d_{\mathrm{D}}\right| \leqq 0.01 \AA$ and $\left|\varphi_{\mathrm{H}}-\varphi_{\mathrm{D}}\right| \leqq 1^{\circ}$ an upper limit to the error in a, caused by this uncertainty, is $0.008 \AA$. Therefore,

$$
a=1.595 \pm 0.010 \AA \text {. }
$$

By inserting in (8) and (9) it is found that

and that

$$
\begin{aligned}
& d_{\mathrm{H}} \cos \varphi_{\mathrm{H}}=0.476 \pm 0.040 \AA \\
& d_{\mathrm{D}} \cos \varphi_{\mathrm{D}}=0.474 \pm 0.020 \AA
\end{aligned}
$$


i. e. these products are about equal to the corresponding quantities for the silyl chlorides although the uncertainty is larger due to lacking experimental data. As shown by Bak, Bruhn and Rastrup-Andersen ${ }^{12}$ by their graphical method it can be shown that if it is assumed that also in this case $d_{\mathbf{H}}-d_{\mathfrak{D}} \sim 0.01$ $\AA, \varphi_{\mathrm{H}}$ and $\varphi_{\mathrm{D}}$ come very close to the tetrahedral value $70^{\circ} 32^{\prime}$. But it is impossible to give $\left|\varphi_{\mathrm{H}}-70^{\circ} 32^{\prime}\right|$ and $\left|\varphi_{\mathrm{D}}-\varphi_{\mathrm{H}}\right|$ with any satisfactory degree of accuracy.

\section{REFERENCES}

1. Kipping, F. S. J. Chem. Soc. 91 (1907) 209, 717.

2. Hassel, O. and Kringstad, H. Z. physik. Chem. B 13 (1931) 1.

3. Tindal, C. H., Straley, J. W. and Nielsen, H. H. Phys. Rev. 62 (1942) 151.

4. Spitzer, R., Howell, W. J. and Schoemaker, J. J. Am. Chem. Soc. 64 (1942) 62.

5. Brockway, L. O. and Coop, I. E. Trans. Faraday Soc. 34 (1938) 1429.

6. Brockway, L. O. and Beach, J. Y. J. Am. Chem. Soc. 60 (1938) 1836.

7. Sharbaugh, A. H. Phys. Rev. 74 (1948) 1870.

8. Dailey, B. P., Mays, J. M. and Townes, C. H. Phys. Rev. 76 (1949) 137, 472, 700.

9. Sharbaugh, A. H., Thomas, V. G. and Pritchard, B. J. Phys. Rev. 78 (1950) 64.

10. Miller, S. L., Aamodt, L. C., Dousmanis, G., Townes, C. H. and Kraitchman, J. J. Chem. Phys. 20 (1952) 1112.

11. Monfils, A. Compt. rend. 236 (1953) 795.

12. Bak, B., Bruhn, J. and Rastrup-Andersen, J. J. Chem. Phys. 21 (1953) 752.

Received December 4, 1953. 